\title{
Analyzing Extents and Determinants of Economic Efficiency of Farm Households in Metekel Zone, Western Ethiopia: Data Envelopment Approach
}

\author{
Shumet Asefa Kibret (Ph.D) \\ Assistant Professor of Economics, College of Business and Economics, Mekdela Amba University, Ethiopia
}

\begin{abstract}
The study investigated extents and major determinants of economic efficiency of farmers in Metekel zone, western Ethiopia using 2016 rural survey. Multi-stage random technique was used to collect data of 420 farmers. Based on the results of data envelopment approach, the average technical efficiency score of farmers was found as 0.738 and hence they forgone a total income of 7,212.79 Birr. The mean allocative efficiency score was found as 0.350 and hence there is a considerable room to reduce their allocative errors. The mean economic efficiency score was found as 0.256 and hence they can reduce their observed costs by 74.4 percent through reducing their cost inefficiency. The results of Tobit model revealed that family size (+), farm size square (-), livestock size $(+)$, land fragmentation (-), crop diversification $(+)$ and sharecropping $(-)$ were found to have significant effect on economic efficiency of farmers. Therefore, the study forwarded policy suggestions for the concerned bodies to: make further efforts in strengthen mixed crop-livestock farming system with better market infrastructures; train farmers to diversify their crop for risk minimization and market surplus; strengthen tenancy security for sharecroppers; consolidate fragmented plots; give top priority in expanding health services; formulate appropriate strategies for expanding rural farm credit facility; expand off/non-farm job opportunities; and provide an appropriate extension services and agricultural information.
\end{abstract}

Keywords: DEA, Economic Efficiency, Farm Households, Tobit Model, Metekel zone, Western Ethiopia

DOI: $10.7176 / \mathrm{JESD} / 10-11-04$

Publication date: June $30^{\text {th }} 2019$

\section{Introduction}

The Government of Ethiopia uses agriculture-led industrial development to leading light the country's development program which the sector of the GDP that determine the pillar of Ethiopia economy and it provide employment opportunity for more than $85 \%$ of the country's population and the primary income-generating sector for the common of the rural population and accounts for more than $45.9 \%$ of the total GDP of the country. It also serves as the main source of food, generates $90 \%$ of the foreign exchange earnings and also provides raw materials for more than $70 \%$ of the country's industries with in agriculture, $60 \%$ of the output of the agricultural GDP comes from crop production whereas, $30 \%$ and $7 \%$ is from livestock and forestry, respectively (World Bank, 2012).

However, lower contribution of agriculture to GDP while employing the majority of the population is an indication of its low productivity. This low productivity is outsourced from the limited usage of improved and modern inputs, extreme dependence on traditional technology, erratic rainfall, poor and degrading soil fertility, chronic plant and animal diseases, high land degradation and fragmentation, and weak supplementary institutional services. Currently, Ethiopian government has been giving much effort in promoting agricultural productivity and efficiency of the smallholder farmers through introduction of modern and yield-enhancing inputs as well as institutional interventions. The growth of agriculture sector via Agricultural Development Led Industrialization (ADLI) strategy can have a spillover effect on the growth of others sectors, particularly on the manufacturing sector. However, agricultural productivity in Ethiopia is still very low even compared to other SSA countries (Arega and Rashid, 2003; Bamlaku et al., 2009; Megos, 2013; Ethiopian Government Portal, 2014).

Agricultural output can be increased either through dissemination of modern technologies, appropriate marketing output price, or by improving the efficiency of inputs such as labor and management at the existing technology. Which means, productivity can be increased through introducing improved technologies, Agricultural inputs (fertilizers, improved variety of seed, mechanized technology, pest sides) and/or by applying appropriate extension service (improved practice, crop protection, and crop management). These three are not exclusive because the introduction of modern technology could not bring the expected shift of production frontier, if the existing level of efficiency is low. This implies the need for the integration of modern technologies with improved level of efficiency. If farmers are sufficiently efficient then increases in productivity require new inputs and technology to shift the production possibility frontier upward. But, on the other hand, if there are significant opportunities to increase productivity through more efficient use of farmers' resources and inputs with proper modern technology, and have got proper market for their output a stronger case could be made for productivity improvement through ameliorating the factors or determinants of inefficiency. 


\section{Rational of the Study}

Poverty in Ethiopia have been mainly related to poor agricultural productivity due to its structural rigidity and mainly managed by smallholder farmers who make non-separable production and consumption decisions (Devereux and Goethe, 2009). Like most developing countries, the average observed yields of cereal crops in Ethiopia are lower than their potential yields. Heavy dependence on traditional technology, weather risks, poor infrastructures, limited institutional services, and poor agricultural policies have been the principal causes of food insecurity in Ethiopia. This clearly reveals the existence of huge potential for rising efficiency and hence productivity of farmers by solving production constraints and a more efficient use of the available inputs at the existing technology (EEA, 2012; Beyan et al., 2013).

Empirical studies in the areas of production efficiency vary in their methodological frameworks, areas of emphasis, and empirical results. However, empirical researches on estimating farm specific level of efficiency in developing countries are scarce. Similarly in Ethiopia, such studies are not extensive. To mention them: Seyoum et al. (1998), Fikadu (2004), Tsegaye and Berg (2005), Arega et al. (2006), Bamilaku et al. (2009), Makombe et al. (2011), Gebrehawaria et al.(2012), Shumet (2012), Beyan et al. (2013), Endrias et al. (2013), Getachew and Bamlak (2014), Mohammed and Kidanemariam (2014), Wondimu and Hassen (2014), and Hassen et al. (2015). All in all, their common features are: (1) majority of these studies entirely focused on technical efficiency of farmers and hence there is dearth of empirical literatures on allocative efficiency and economic efficiency; (2) majority of these studies applied parametric stochastic frontier analysis (SFA) and hence limited attention was given for non-parametric data envelopment analysis (DEA); (3) majority of these studies given limited attention to the determinants of one components of efficiency; and (4) majority of these studies were conducted on specific crops. Given various advantageous and drawbacks of the SFA and DEA approaches, DEA is chosen to best fit the data set. To best of the existing information, no similar studies had been conducted so far in the study area. Therefore, to fill the above gaps and to add stock of knowledge in literature, this study brought new estimates of the extent of economic efficiency scores of smallholder farmers using DEA technique, and hence analyzed its principal determinants using two-limit Tobit model in Metekel zone, Western Ethiopia.

\section{Objective of the Study}

The main objective of the study is to investigate extents and major determinants of economic efficiency scores of farm households in Metekel zone, Western Ethiopia using non-parametric Data Envelopment Approach (DEA) technique.

The specific objectives of this study are:

1.To analyze the extent of economic efficiency of farm households in Metekel zone, Western Ethiopia, and

2.To investigate major determinants of economic efficiency of farm households in Metekel zone, Western Ethiopia.

\section{Research Design and Methodology \\ 4.1. Description of Study Area}

Ethiopian, which is a sovereign state in the horn of Africa, is divided into nine regional states which are further divided into zones and woredas. Benishangul-Gumuz was established as regional state in 1994. The region is divided into three administrative zones and twenty woredas. Metekel zone is the study area that consists of seven woredas with an area of about $26,560 \mathrm{~km}^{2}$ and altitude ranged from 600 masl to 2800 masl. About two-third of the zone is characterized by sub-humid and humid tropical low-land agro-climate. It has a total population of around 403,216 people with 81,919 farm household heads. The average family size of zone is around six. The population density of the zone is about 15.48 persons $/ \mathrm{km}^{2}$, i.e., the zone is relatively sparsely populated (CSA, 2013). This zone is located $550 \mathrm{~km}$ West of Addis Ababa, which is the Ethiopian capital city. This zone is dominated by the traditional mixed crop-livestock production system. Dominantly grown cereal crops in the study area are: maize, sorghum, rice and millet. Other oil crops produced are: sesame, niger seed, groundnuts, haricot beans, chickpeas, and soya beans (Solomon et al., 2014).

\subsection{Sources and Methods of Data Collection}

The study used multi-stage random sampling technique to collect farm household data in 2015/16 production season. The study used pre-tested structured questionnaire and three extension workers (those experts who have been specialized in crop, livestock, and resources management) for each chosen kebele in the three districts. The study randomly selected 30 farm households from each kebele. And hence, the study collected the required farm data from the total 420 farm households from 14 kebeles in 2015/2016 production season. From the total respondents, 285 farm households (67.86 percent) are resettled and the remaining 135 farm households (32.14 percent) are non-resettled households. 


\subsection{Empirical Model Specification and Data Analysis}

\subsubsection{Non-Parametric Data Envelopment Approach}

The DEA method constructs a non-parametric production frontier over the data. Charnes et al. (1978) proposed input-orientated CRS DEA to simultaneously construct frontier with the aim of minimizing inputs with the given level of output. The CRS assumption is only appropriate when all DMUs are operating at an optimal scale. Imperfect competition, government regulation, credit constraints, etc., may cause a DMU to be not operating at optimal scale. Banker et al. (1984) suggested an extension of the CRS DEA model to account for variable returns to scale (VRS). The use of VRS DEA model enables to calculate TE devoid of scale efficiency effect. Note that the farm households in the study areas have relatively direct control on inputs and faced resource shortages so that the study gets input-oriented approach more important than output-oriented. In addition, VRS is found to be more appropriate than its CRS counterpart for measuring efficiency. The CRS linear programming problem can be easily relaxed to take in to account for VRS technology by adding the convexity constraint: $\mathrm{N} 1^{\prime} \lambda=1$ to equation (4) as follow:

$$
\begin{array}{r}
\min _{\theta, \lambda} \theta_{i} \\
\text { Subject to } \\
-\mathrm{y}_{\mathrm{i}}+\mathrm{Y} \lambda \geq 0 \\
\theta x_{i}-\mathrm{X} \lambda \geq 0 \\
\mathrm{~N} 1^{\prime} \lambda=1 \\
\theta \geq 0, \lambda \geq 0
\end{array}
$$

Where,

$\theta_{\mathrm{i}}$ : it refers to the technical efficiency score of the $\mathrm{i}^{\text {th }} \mathrm{DMU}$,

$\mathrm{N} 1^{\prime} \lambda=1$ : it refers to a convexity constraint which ensures that an inefficient farm household is only benchmarked against farm household of a similar size,

$\mathrm{N} 1:$ it refers to an $\mathrm{N} \times 1$ vector of ones,

Y: it refers to the output matrix for all N DMUs,

$\mathrm{y}_{\mathrm{i}}$ : it refers to the total value of output of $\mathrm{i}^{\text {th }} \mathrm{DMU}$ in Birr,

$\mathrm{X}$ : it refers to the input matrix for all N DMUs,

$\mathrm{x}_{\mathrm{i}}$ : it refers to the vector of convectional inputs of $\mathrm{i}^{\text {th }} \mathrm{DMU}$, and

$\lambda$ : it refers to a Nx1 constants.

VRS DEA forms a convex hull plane which envelops the data points more tightly than the CRS DEA and thus provides efficiency scores greater than or equal to CRS DEA. Estimating CRS DEA model gives the 'overall TE' scores, while VRS DEA model calculates only pure TE scores which capture the management practices of DMUs. The residual between overall TE and pure TE scores shows scale efficiency. The overall technical inefficiency can be decomposed into two components: one is due to scale inefficiency and the other due to pure technical inefficiency (Coelli et al, 2002). Mathematically it can be expressed as:

$$
\mathrm{SE}=\frac{\mathrm{TE}_{\mathrm{CRS}}}{\mathrm{TE}}
$$

Economic efficiency can be computed as the ratio of the frontier cost to the actual cost. The frontier cost can be calculated by using a cost minimization DEA model as follow (Coelli et al., 1998):

$$
\begin{gathered}
\min _{\lambda, \mathrm{X}_{\mathrm{i}}^{*}} \mathrm{~W}_{\mathrm{i}}^{*} \mathrm{X}_{\mathrm{i}}^{*} \\
\text { Subject to } \\
-\mathrm{y}_{\mathrm{i}}+\mathrm{Y} \lambda \geq 0 \\
\mathrm{X}_{\mathrm{i}}^{*}-\mathrm{X} \lambda \geq 0 \\
\mathrm{~N} 1^{\prime} \lambda=1 \\
\lambda \geq 0 \ldots
\end{gathered}
$$

Where $\mathrm{W}_{\mathrm{i}}^{*}$ is a vector of input prices for the $\mathrm{i}^{\text {th }} \mathrm{DMU}$ and $X_{i}^{*}$ is a vector of input quantities that minimize the cost of production of the $i^{\text {th }}$ DMU, given the input prices $W_{i}^{*}$ and the adjusted value of observed output level of the $\mathrm{i}^{\text {th }} \mathrm{DMU}, \mathrm{y}$. In the similar analogy, according to according to Sharma et al. (1999), economic efficiency (EE) can also be computed as:

$$
\mathrm{EE}=\frac{\text { Frontier cost }}{\text { Observed cost }} \text {, i.e., } \mathrm{EE}=\frac{\mathrm{W}_{\mathrm{i}}^{*} \mathrm{X}_{\mathrm{i}}^{*}}{\mathrm{~W}_{\mathrm{i}}^{*} \mathrm{X}_{\mathrm{i}}}
$$

Allocative efficiency score $\left(\mathrm{AE}_{\mathrm{i}}\right)$ of the $\mathrm{i}^{\text {th }} \mathrm{DMU}$ is estimated as residual by taking the ratio of economic efficiency score $\left(E_{i}\right)$ of the $i^{\text {th }} D M U$ and technical efficiency score $\left(\mathrm{TE}_{\mathrm{i}}\right)$ of the $\mathrm{i}^{\text {th }} \mathrm{DMU}$ as follow:

$$
\mathrm{AE}_{\mathrm{i}}=\frac{\mathrm{EE}_{\mathrm{i}}}{\mathrm{TE}_{\mathrm{i}}}=\frac{E E_{i}}{\theta_{i}}=\frac{\mathrm{W}_{\mathrm{i}}^{*} \mathrm{X}_{\mathrm{i}}^{*}}{\theta_{\mathrm{i}}\left(\mathrm{W}_{\mathrm{i}}^{*} \mathrm{X}_{\mathrm{i}}\right)}
$$


Where,

$\theta_{\mathrm{i}}:$ it refers to the technical efficiency score $\left(\mathrm{TE}_{\mathrm{i}}\right)$ of the $\mathrm{i}^{\text {th }} \mathrm{DMU}$,

$\mathrm{W}_{\mathrm{i}}^{*} \mathrm{X}_{\mathrm{i}}^{*}$ : it refers to the economically efficient cost of production of the $\mathrm{i}^{\text {th }} \mathrm{DMU}$,

$\mathrm{W}_{\mathrm{i}}^{*} \mathrm{X}_{\mathrm{i}}$ : it refers to the observed cost of production of the $\mathrm{i}^{\text {th }} \mathrm{DMU}$, and

$\frac{W_{i}^{*} X_{i}^{*}}{W_{i}^{*} X_{i}}$ : it refers to the ratio of economically efficient cost of production of the $i^{\text {th }}$ DMU and the observed cost of production of the $\mathrm{i}^{\text {th }}$ DMU, which refers to the economic efficiency score of the $\mathrm{i}^{\text {th }}$ DMU.

\subsubsection{The Two-Limit Tobit Model}

As vital inputs for policy formulation, reporting only estimated efficiency scores of farm households are intermediate results. So investigating principal factors that are supposed to be major source of variation of economic efficiency scores among the farmers is vital. The main aim of this analysis is to answer whether this efficiency variability can be attributed to the principal internal factors which are under the control of farm households in the study area or not.

Following the empirical works of Amemiya (1985) and Binam et al. (2005), the two limit-Tobit regression model is expressed as follow:

Where,

$$
\mathrm{Y}_{\mathrm{i}}^{*}=\beta_{0}+\beta_{\mathrm{j}} \mathrm{Z}_{\mathrm{i}}+\mu_{\mathrm{i}}
$$

$Y_{i}{ }^{*}$ : it refers to a latent value for the economic efficiency scores of the $i^{\text {th }}$ farm household, separately,

$\beta_{\mathrm{j}}$ : it refers to a vector of $\mathrm{j}$ parameters to be estimated using maximum likelihood estimation (MLE) method,

$\mathrm{Z}_{\mathrm{i}}$ : it refers to a vector of $\mathrm{j}$ demographic, socio-economic, environmental and institutional related farm specific explanatory variables of the $i^{\text {th }}$ farm household, and

$\mu_{\mathrm{i}}$ : it refers to a random error term that is independently and normally distributed with mean zero and variance $\sigma^{2}$ of the $\mathrm{i}^{\text {th }}$ farm household.

The estimated values of economic efficiency scores of the $i^{\text {th }}$ farm household is double censored from both lower and upper sides. The maximum likelihood estimation (MLE) is then used to obtain unbiased and consistent estimate of the unknown parameters of the Two-Limit Censored Tobit model.

\section{Results and Discussion}

\subsection{Descriptive Statistics of Demographic Related Variables}

The results of descriptive statistics in the above table reveal that 91.7 percent of the respondents are male headed farmers and average age of the respondents is 39 years with an average farming experience of 22 years. The average formal schooling of farmers was found as 3 years and only 44 percent of the family members are formally educated. From the total respondents, 208 (49.5 percent) households are headed by illiterate farmers without basic education. The average family size was found to be 6 and hence 42 percent of the family members are dependents. In addition, the result reveals that 69 percent of the farmers faced health problems. This really confirms the fact that the study area is sub-humid and humid tropical lowland area which is characterized by high incidence of malaria. From the total respondents, only 22 percent had access to irrigation, 30 percent had access to credit, 50 percent used improved technology, 21 percent used sharecropping, and 46 percent are members to farmers' association. In addition, respondents have an average of 14 annual contacts with extension agents, an average farm size of 3.83 hectares, an average livestock size of 5 in terms of TLU, and 49 percent have engaged in off/non-farm activities.

\subsection{Measurement of Economic Efficiency of Farm Households}

Multicollinearity test was undertaken for the dual Cobb-Douglass cost frontier via VIF test. Since there are no substantial variations in between prices of Urea and DAP across farm households in the study area, the result of VIF claimed collinearity problem in between prices of these two inputs while the VIF for other variables were found to be less than ten. However, collinearity problem was not detected between Urea and DAP physical values under Cobb-Douglass production frontier. Heterosckedasticity test was checked using Breusch-Pagan test. Since the hypothesis that claimed constant variance is rejected, as its p-value is found to be significant at 5 percent level, the study used robust standard error, which is theoretically supported as remedial solution. The third important test used is omitted variable test via Ramsey RESET F-test. Since the p-value of this test is found to be insignificant at 5 percent level $(p=0.27)$, then hypothesis that claimed as the cost function has no omitted variables could not be rejected.

For resettled farm households, based on the results of MLE of Cobb-Douglass cost frontier, price of land with the estimated cost elasticity of 0.64 , was found to have considerable effect on their cost of production at 1 percent significance level. This is followed by value of output adjusted for stochastic noises with estimated cost elasticity 
of 0.50 at 1 percent level, by price of oxen drought power with estimated cost elasticity of 0.45 at 5 percent significance level, by price of improved seed with estimated cost elasticity of 0.16 at 10 percent significance level, and then finally by price of manure fertilizer with estimated cost elasticity of -0.16 at 10 percent level, respectively. Here the reason for the negative effect of price of manure on the cost of production of resettled farmers may be due to the fact that manure fertilizer is non-marketable home-prepared from animal dungs and hence has minimal effect on their cost of production. While for existing farm households, price of output adjusted for stochastic noises, with the estimated cost elasticity of 0.47 , was found to have considerable effect on their cost of production at 1 percent level followed by price of land with estimated cost elasticity of 0.26 at 10 percent level, and then by price of improved seed with estimated cost elasticity of 0.21 at 10 percent significance level.

The mean economic efficiency scores of resettled and existing farmers were found as 25.6 percent and 28.9 percent, respectively and hence, they have potentials to reduce their average observed production costs by 74.4 percent and 71.1 percent, respectively but still producing same level of output with the given current technology if they would be fully cost efficient. In addition, the average resettled farmer could reduce his/her production cost by 24.71 percent [i.e., $1-\left(\frac{0.256}{0.340}\right) * 100$ ] if he/she could achieve the EE level of his/her most efficient counterpart with the given level of output and current technology. A similar calculation for the most cost inefficient resettled farmer shows that he/she could achieve cost saving by 92.10 percent [i.e., $1-\left(\frac{0.027}{0.340}\right) * 100$ ] if he/she could achieve the EE level of his/her most efficient counterpart. The empirical findings showed that considerable level of economic inefficiency of farmers in crop production is attributed to allocative inefficiency.

\subsection{Determinants of Economic Efficiency of Farm Households}

\subsubsection{Determinants of Economic Efficiency of Resettled Farmers}

Family Size: The result MLE implied that family size was found with significantly effect, with coefficient of 0.01 , on EE of resettled farmers at 1 percent level. This is due to the fact that family has more adult members who allocate more of their time to off/non-farm activities. In addition, having large family size may result divergent interests among family members regarding to consumption of resources which could lead excess production cost and lower economic efficiency.

Farm Size Square: It was found to have significant and negative effect on EE at 10 percent level. This shows that as land size increases further, the EE will be decreased. This could be due to the fact as the plot size becomes larger, the probability of having fragmented lands will be higher and hence cultivating these large fragmented plots will require more resources than small plot size. This is supported by the significant and negative effect of land fragmentation on EE. And hence, small farmers could have the possibility to use their resources in more cost effective manner on their cultivated lands.

Livestock Size: The MLE result showed that livestock size of the resettled farmers was found to have significant effect, with coefficient of 0.003 , on their EE at 5 percent level. This is due to the fact that resettled farmers who possess more number of livestock invest the money generated from selling their livestock and/or livestock byproducts on improved inputs. In addition, livestock also used for threshing, transporting inputs and outputs, and homemade fertilizer in the form of animal dungs.

Land Fragmentation: The result of MLE showed that land fragmentation was found to have significant effect on EE of resettled farmers, with coefficient of -0.01 , at 1 percent level. The possible reason might be that due to the difficulty of managing and applying modern technology efficiently on fragmented plots effectively and hence they are expected to lose more of their time by moving between plots. This could lead to wastages of resources and hinder to use cost-minimizing input mixes.

Pawe District: The result of MLE showed that the coefficient of Pawe district, - 0.05 , was found as significant at 1 percent level. The possible reason for this difference might be due to the fact that newly resettled farmers reside in Mandura district have been given better support and follow up from regional government and NGOs in the form of better extension service via farmers training center (FTC), distribution of improved inputs, and irrigation potential as compared to its counterpart. In addition Mandura district is endowed with more fertile cultivable land than Pawe district.

Crop Diversification: The result of MLE revealed that crop diversification was found to have significant effect, with coefficient of 0.02 , on EE of resettled farmers at 1 percent level. This is due to the fact that planting various locally adapted crop varieties, which regarded as risk minimization strategy during crop failure, could enable the farmers to allocate their available scarce resources more efficiently and also to enhance soil fertility which will enable them to achieve more economic efficiency than their counterparts.

Sharecropping Status: The result of MLE showed that sharecropping status was found as significant at 5 percent level with coefficient of 0.03 . This may be due to the prevalence of tenancy insecurity. Since all amount produced will be shared by land owner based on their contractual agreement, the tenant has the tendency not to exert his/her full effort and resources because of his/her limited incentive to make long-term investment on land. In addition, 
due to uncertainty the tenant is more probably reluctant to use improved and environmentally friendly farming techniques.

\subsubsection{Determinants of Economic Efficiency of Existing Farmers}

Education of the Farmer: The MLE result revealed that education was found to enhance EE of existing farmers significantly, with coefficient of 0.04 , at 10 percent level. This is because it can increase their information acquisition and management abilities, thereby-increasing their awareness regarding opportunities for productive employment and rational decision-making for optimal resource allocation.

Health Status: The result of MLE revealed that health status was found as significant, with coefficient of 0.03 , at 10 percent level. This is because patient farmers were less likely to be physically fit to timely and effectively undertake farming activities especially during peak period. And hence, existing farmers who faced health problem will divert their resources for health expenditures which could reduce their crop production and EE.

Off/non-Farm Income: The result of MLE revealed that off/non-farm activity was found as significant, with coefficient of 0.03 , at 10 percent level. This is due to the fact that in poor functioning credit market, participating in non-farm income activities will enable farmers to relax their liquidity constraints there by invest their non-farm incomes on modern inputs that can improve their crop production and hence their EE.

Land Fragmentation: The MLE result showed that land fragmentation was found to have significant effect on EE of existing farmers, with coefficient of -0.01 , at 10 percent level. The possible reason might be that due to the difficulty of managing and applying modern technology efficiently on fragmented plots effectively and hence they are expected to lose more of their time by moving between plots. This could lead to wastages of resources and hinder to use cost-minimizing input mix in crop production.

Pawe District: The result of MLE showed that the coefficient of Pawe district, with coefficient of -0.07 , was found as significant at 5 percent level. The possible reason for this difference might be due to the fact that farmers reside in Mandura district have been given better support and follow up from regional government and NGOs in the form of better extension service, distribution of improved inputs, and irrigation potential. In addition, Mandura district is endowed with more fertile land.

Credit Access: The result of MLE showed that credit access was found to have negative and significant effect on EE of existing farmers, with coefficient of -0.07 , at 5 percent level. This reveals that existing farmers are not using the loan for the targeted farming activities. The loan diversion to non-farming activities is due to small loan size and difficulty of accessing load on critical time like peak season due to higher interest rate, unable to repay their previous loan and unavailability of loan in some localities.

Sources of Information: The result of MLE revealed that source of information was found to have significant effect, with coefficient of 0.009 , on EE of existing farmers at 10 percent level. This is possibly due to the fact that existing farmers with access to varieties of sources of information about farm business are more likely to access information about price of inputs and output, improved technologies and hence more likely to use them for enhancing their productivity and hence more likely to have cost minimizing skills.

\section{Conclusions and Policy Implications}

Since improving resource use efficiency of farmers will lead to boost their productivity and hence their food security there by achieving sustainable economic growth, the study forwarded the following policy suggestions, based on our empirical findings, for the government and other concerned bodies. Such policy implications may be useful in designing effective policies for enhancing productive efficiency of farmers and hence their crop production there by achieving their livelihood sustainability and hence poverty reduction objectives of the study area in particular and the country in general.

1. As family size was found to have significant diminishing effect on economic efficiency of farmers, then existing family planning program should further be strengthened and outreached its coverage in the study area.

2. Livestock ownership in general and oxen in particular have significant supplementary effect on both crop production and hence on economic efficiency of farmers via investing the money generated from selling their livestock and/or livestock by-products on modern inputs. Therefore, government officials should draw appropriate strategies that are vital for strengthening the integrated crop-livestock farming system, increasing and sustaining their crop and livestock productivity, investing on market infrastructures to easily find profitable markets for their crop and animal products, and reducing livestock related diseases in the study area.

3. As crop diversification was found to have significant positive effect on economic efficiency of farmers, then extension development agents should train and encourage farmers to diversify their crop varieties for sake of risk minimization during crop failure and surplus for market, to allocate their existing scarce resources more efficiently, and also to sustain and enhance soil fertility.

4. Since small land holders were found to have higher economic efficiency than large land holders, then government should give priority in supporting small holder farmers who dominated the farming sector. It 
is known that large portion of the rise in crop production in the country has been related with increases in land size. However, declining land holding size has been critical problem due to alarmingly rising population and continuous land fragmentation. The feasible solution to the rising food insecurity and declining agricultural productivity problems is improving land productivity via intensive farming and applying environmentally sound technology that can raise and sustain soil fertility in subsistence farming as 60 percent of the sampled farmers replied they faced continuous deterioration of soil fertility.

5. The farmers who cultivated sharecropped land were found to have significantly lower economic efficiency. Therefore, it is necessary to strengthen tenancy security for sharecroppers via strongly binding and longterm contractual agreements for sake of most efficient land usages. In addition, consolidating fragmented plots and training farmers to use sound land management practices is vital as 61 percent of the farmers replied they faced farm land shortages.

6. The farmers with health problems during production season were found to have significantly lowered economic efficiency. Therefore, the concerned bodies should give top priority to expand health service coverage and provide appropriate health services to the farmers. This can be confirmed by the fact that the study area is sub-humid and humid tropical low-land with high incidence of malaria.

7. Since access to credit was found to have significant competitive effect on economic efficiency of farmers, then policy makers should formulate appropriate strategies to expand and intensified better credit facility via establishment of adequate rural finance institutions and strengthening of the already available microfinance institutions and agricultural cooperatives. The most important strategy needed enhance agricultural productivity is to train farmers in the study area to properly use their loan for farming activities, timely provision of the required credit amount in subsidized loan rate so as to liquidate credit constraints of farmers in accessing improved and modern inputs.

8. The farmers' engagement in off/non-farm activities was found to have significant supplementary effect on their economic efficiency. Therefore, then appropriate strategies need to be drawn and give focus on expanding access to off/non-farm employment opportunities. Such activities will help farmers to allocate their underemployed labor to productive off/non-farm activities as well as to invest their off/non-farm incomes on improved and modern agricultural inputs that can enhance crop production and hence overall wellbeing of the rural farming societies.

9. As access to information was found to have significant enhancing effect on economic efficiency of farmers, then the concerned bodies should expand and diversify farmers' sources of agricultural information. This is because this will help farmers in the study area to be endowed with information about market prices, awareness and easy access to high yielding variety of improved and modern technologies.

10. Last but not least, the concerned bodies should design district specific supportive strategies as they have farm specific differences in production environment, institutions, and market infrastructures that brought considerable difference in their productivity and efficiency.

\section{References}

Aigner, D.J., Lovell, C.A.K., and Schmidt, P. (1977). Formulation and Estimation of $\quad$ Stochastic Frontier Production Function Models. Journal of Econometrics, Vol.6, pp: 21-37.

Asrat, T. (2009). The Dynamics of Resettlement with Reference to Ethiopian Experience. Development Studies Centre, pp: 1-22, Dublin, Ireland.

Banker, R.D., Charnes, A., and Cooper, W.W. (1984). Some Models for Estimating Technical and Allocative Efficiencies in Data Envelopment Analysis, Management Science, Vol. 30, pp: 1078-1092.

Begum, I. A., Buysse, J., Alam, M. J., and Huylenbroeck, G. V. (2009). An application of Data Envelopment Analysis (DEA) to Evaluate Economic Efficiency of Poultry Farms in Bangladesh. Contributed Paper prepared for presentation at the International Association of Agricultural Economists Conference, Beijing, China, August 16-22, 2009.

Bravo-Ureta, B.E. and Pinheiro, A.E. (1997). Technical, Economic and Allocative Efficiency in Peasant Farming: Evidence from Dominica Republic. The Developing Economics, Vol. xxxv-1, pp: 48-67. Cambridge University Press, Cambridge.

Central Statistical Agency (CSA) (2013). Population Projection of Ethiopia for All Regions at Wereda Level from $2014-2017$.

Charnes, A., Cooper, W.W., and Rhodes, E. (1978). Measuring the Efficiency of Decision Making Units. European Journal Operational Research, Vol. 2, pp: 429-444.

Coelli, T.J. (1995). Recent Developments in Frontier Modeling and Efficiency Measurement. Australian Journal of Agricultural Economics, Vol. 39, No. 3, pp: 1-23.

Coelli, T.J, Rahman, S., and Thirtle, C. (2002). Technical, Allocative, Cost and Scale Efficiencies in Bangladesh Rice Cultivation: A Non-parametric Approach. Journal of Agricultural Economics, Vol. 53, No.3, pp: 607626. 
Coelli, T.J, Rao, D.S.P., O’Donnell, C.J., and Battese G. (2005). An Introduction to Efficiency and Productivity Analysis. Centre for Efficiency and Productivity Analysis, Second Edition, pp.1-326, Springer, University of Queensland Brisbane, Australia.

Coelli, T.J., Rao, D.S.P., and Battese, G. E. (1998). An Introduction to Efficiency and Productivity Analysis. Kluwer Academic Publishers, Boston, Dordrecht/London, pp: 134 - 249.

Ethiopian Government Portal (EGP) (2014). Federal Democratic republic of Ethiopia. Accessed at http://www.ethiopia.gov.et on 26 December, 2014.

Farrell, M. J. (1957). The Measurement of Productive Efficiency. Journal of the Royal Statistical Society, Vol .120, No.3, pp: 253-281

Gebre, Y. (2002). Differential Reestablishment of Voluntary and Involuntary Migrants: The Case of Metekel Settlers in Ethiopia. African Study Monographs, Vol.23, No.1, pp: 31-46. Graduate School of Asian and African Area Studies, Kyoto University.

Kassa, T. A. (2015). Resettlement and Sustainable Livelihoods in Ethiopia: A Comparative Analysis of Amhara and Southern Regions. A PhD Thesis Submitted to the School of Graduate Studies of University of South Africa, South Africa.

Meeusen, W. and Van Den Broeck, J. (1977). Efficiency Estimation from Cobb-Douglas Production Functions with Composed Error. International Economic Review, Vol.18, No.2, pp: 435- 444.

Schultz, T.W. (1964). Transforming Traditional Agriculture. Yale University Press. New Haven. CT.

Sharma, A. R., Leung, P., and. Zaleski, H.M. (1999). Technical, allocative and economic efficiencies in swine production in Hawaii: A comparison of parametric \& non-parametric approaches. Agricultural Economics, Vol. 20, pp: 23-35.

Solomon, Z A., Binyam, K., Bilatu, A., Ferede, A., and Gadisa, M. (2014). Smallholder Cattle Production Systems in Metekel Zone, Northwest Ethiopia. Research Journal of Agriculture and Environmental Management, Vol.3, No.2, pp.151-157.

World Factbook (2004). Ethiopian Society's Resettlement and Villagization Programs. United States Central Intelligence Agency (CIA). Accessed at http://www.photius.com on 19/06/2016.

Yu, B. and Nin-Pratt, A. (2011). Agricultural Productivity and Policies in Sub-Saharan Africa. Selected Paper prepared for presentation at the Agricultural and Applied Economics Association's 2011 AAEA and NAREA Joint Annual Meeting, July 24-26, 2011, Pittsburgh, Pennsylvania. 